\title{
A DESCRIPTIVE STUDY ON NUTRITIONAL STATUS ASSESSMENT AND MORBIDITY PATTERN OF ADOLESCENTS (10-16 YEARS) RESIDING IN URBAN SLUMS OF AMRITSAR, PUNJAB
}

\author{
JASMEET SINGH ${ }^{1}$, SANJEEV MAHAJAN ${ }^{1}$, DEEPTI SS ${ }^{1}$, TEJBIR SINGH ${ }^{1}$, RUCHIKA KUMARI ${ }^{2}$, PREETI PADDA1*
}

${ }^{1}$ Department of Community Medicine,Government Medical College, Amritsar, Punjab, India. ${ }^{2}$ Department of Obstetrics and Gynecology, Fortis Escorts Hospital, Amritsar, Punjab, India. Email: drpreetipadda@gmail.com

Received: 30 June 2021, Revised and Accepted: 07 August 2021

\section{ABSTRACT}

Objectives: To assess the nutritional status and morbidity pattern of adolescents age 10-16 years and to determine the various factors associated with under-nutrition.

Methods: A descriptive cross-sectional study was conducted among 1600 households which were selected by systematic random sampling method from 64 slum areas. All adolescents aged 10-16 years were included. Required information was collected on a pretested performa. Height and weight were measured to assess their nutritional status and haemoglobin estimation was done by Sahli's method. Descriptive statistics (frequencies and proportions) and univariate logistic regression were done to determine various factors associated with under nutrition.

Results: Out of 603 study participants, $75 \%$ of adolescents were under-weight. About $82.3 \%$ had anemia. About $36 \%$ suffered from one or more infectious disease in the last 3 months. Going to school, occupation, female sex, and suffering from any infectious disease in the past 3 months were found to be associated with malnutrition. Addiction was reported in $9 \%$ of study participants.

Conclusions: High prevalence of under-nutrition and anemia in our study reflects inequitable distribution of resources, low purchasing capacity of foods, and unequal food sharing patterns in families making them socially and biologically vulnerable.

Keywords: Malnutrition, Morbidity, Anaemia, Addiction 10-16 year adolescents.

(c) 2021 The Authors. Published by Innovare Academic Sciences Pvt Ltd. This is an open access article under the CC BY license (http://creativecommons.org/ licenses/by/4.0/) DOI: http://dx.doi.org/10.22159/ajpcr.2021v14i9.42694. Journal homepage: https://innovareacademics.in/journals/index.php/ajpcr

\section{INTRODUCTION}

Adolescents in the society constitute critical segment as future demographic, social, economic, and political developments of the entire population are dependent on them and they constitute about $20.9 \%$ of country's population [1]. Adolescent is considered as transitional phase where they transit from childhood to adulthood, which is characterized by physical, psychological, and intellectual growth. Behavioral and social changes also saliently mark the importance of this stage.

The urban sector presently contributes about $62 \%$ of the GDP and this is expected to increase to $75 \%$ by 2021 , still, $30-40 \%$ of the urban population lives in poverty [2]. This inequality of wealth, unplanned urbanization, and migration lead to creation of slums. Slum is a compact area of at least 300 populations or about 60-70 households $(\mathrm{HH})$ of poorly built congested tenements, in unhygienic environment usually with inadequate infrastructure and poor sanitary and drinking water facilities which has a direct impact on the health status of its residents [3].

Impact on adolescents of the poor environmental condition is the maximum especially in early and middle adolescence as they face puberty as well as growth spurt because of which their energy demand increases, in turn making more vulnerable to malnutrition. India is $94^{\text {th }}$ in rank, among 104 countries in hunger index and lies on serious grading on Global hunger index severity scale (20-34.9) [4]. Inadequate nutrition when coupled with unhygienic environment, inadequate infrastructure, and lack of proper sanitary and drinking water facilities are detrimental to safety, health and morals.

More than half (58\%) of adolescent boys and $47 \%$ of adolescent girls are underweight, in our country [5].
Iron deficiency anemia is quite prevalent among adolescents (56\% among adolescent girls and 30\% among adolescent boys) [6]. Further, over $80 \%$ of adolescents also suffer from "hidden hunger," i.e. the deficiency of one or more micronutrients such as iron, folate, zinc, Vitamin A, Vitamin B12, and Vitamin D [7].

Multiple physical, emotional, and social changes, including exposure to poverty, abuse, and violence make adolescents vulnerable to mental health problems and half of the mental health conditions start by 14 years of age, but cases are undetected [8]. Consumption of alcohol and illicit drugs often begins early and then increases during the adolescent years [9].

Therefore, keeping in view the vulnerability of early and middle adolescents towards malnutrition and other morbid conditions, current study was planned to assess the morbidity status (especially, malnutrition, and anemia) of adolescents aged $10-16$ years as well as to determine the factors associated with under nutrition.

\section{METHODS}

Institutional Ethical clearance has been taken before the commencement of the study. Written consent was obtained from all the study participants.

Community-based cross-sectional study was conducted over a period of 1 year in urban slums of district Amritsar. Sampling procedure adopted is shown in Fig. 1.

Assuming the power of study to be $80 \%$, sample size for each selected slum was calculated by using the formula for single proportional i.e.

$$
\mathrm{N}=\frac{\mathrm{Z}_{\alpha / 2}{ }^{2} \mathrm{p}(1-\mathrm{p})}{\mathrm{d}^{2}}
$$


Where $\mathrm{p}=$ expected prevalence/proportion of interest (taken to be $50 \%$ to get maximum sample size)

$\mathrm{d}=$ precision assumed to be $5 \%$

$\mathrm{Z} \alpha / 2=1.96$ (for level of confidence of $95 \%$ )

Therefore, a total of $400 \mathrm{HH}$ were selected from each slum (total sample size $=1600 \mathrm{HH}$ ) using systematic random sampling.

A house-to-house survey was conducted among the selected $\mathrm{HH}$ and all adolescent aged 10-16 years were included in the study after taking written informed consent of mother/guardian. Assent was also taken from adolescents aged 13 years or more. Any HH without an adolescent of age 10-16 years of age and who failed to give an informed consent/ assent were excluded from the study and immediately next $\mathrm{HH}$ in the line list was included to complete the sample. Adolescents with chronic disabilities/disorders and mental retardation were also excluded from the study to remove any bias.

One-to-one interview was conducted with the mother/guardian of the study participant during which information regarding sociodemographic profile of the family was recorded on a pretested, validated, and structured performa. Further information on the educational status, addiction, occupation, disease status in the last 3 months was also gathered from the study participant/mother/ guardian and recorded on the same performa. Height (in $\mathrm{cm}$ ) and weight (in $\mathrm{kg}$ ) were measured and recorded using standardized technique. Digital weighting scale was used to record the weight of child nearest up to $0.5 \mathrm{~kg}$. For recording height of study participants, ISI marked stadiometer was used measuring it nearest up to $0.1 \mathrm{~cm}$.

Nutritional status was assessed using body mass index (BMI) (weight in $\mathrm{kg}$ /height in $\mathrm{m}^{2}$ ). On the basis of BMI, study participants were divided into three categories using Modified Asian criteria of BMI classification, i.e., Under nourished (BMI $<18.5 \mathrm{~kg} / \mathrm{m}^{2}$ ), normal (BMI $18.5-22.9 \mathrm{~kg} / \mathrm{m}^{2}$ ), and overweight (BMI $>23 \mathrm{~kg} / \mathrm{m}^{2}$ ) [10].

Hemoglobin $(\mathrm{Hb})$ estimation was done by Sahli's method and study participants with $\mathrm{Hb}<11 \mathrm{~g} / \mathrm{dl}$ were labeled as anemic. Based on $\mathrm{Hb}$ values, they were graded into mild (10-11 g), moderate (7-9.90 g, and severe $(<7 \mathrm{~g})$ anemia [11].

The data was compiled and analyzed using Epi Info 07 (CDC, USA). Proportions and means were calculated for categorical data and continuous data, respectively. Chi-square test was applied to assess the significant differences across categories. Further univariate logistic regression was applied to determine the factors associated with under nutrition where odds ratio (OR) (95\% confidence interval [CI]) was calculated to get the strength of association.

\section{RESULTS}

Among $1600 \mathrm{HHs}$ surveyed, a total of 603 adolescents in the age group of $10-16$ years were found and $57 \%$ of them were males. Majority $(80 \%)$ were migrants and belonged to upper lower socio-economic

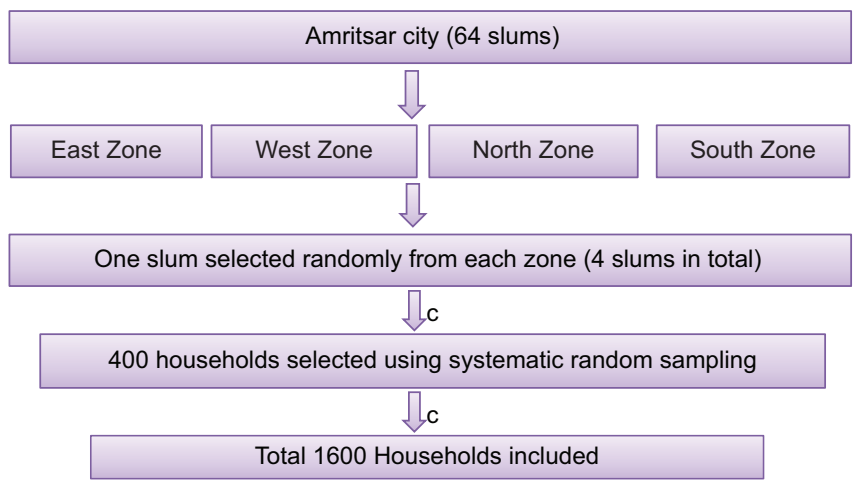

Fig. 1: Sampling technique used in the study status (94.4\%) according to Kuppuswamy scale. Only 18\% (111) of study participants reported to be born in a hospital (institutional delivery) whereas rest i.e., 492 (82\%) were born at home. Overall, $55 \%$ (330) of study participants were currently going to school out of which $54.5 \%$ (180) were male and $45.5 \%$ (150) were female. This difference was not found to be statistically significant. Among all, only $17 \%$ were engaged in any kind of occupation. Majority of these were males $(74 \%$; 76) whereas $26 \%$ (27) were female and this difference was statistically significant $(\mathrm{OR}=2.5 ; 95 \% \mathrm{CI}=1.6-4.0)$. Addiction was reported among 9\% (52) of study participants and all were males.

The prevalence of anemia was found to be $82.3 \%$ (483/587).A total of 16 ( 8 males and 8 females) participants refused to be tested for anemia as they failed to give consent for a finger prick. Anemia was slightly higher among females (85\%) in comparison to males (80\%) but the difference was not statistically significant (OR=1.4; 95\% CI=0.9-2.2). Gender-wise distribution of severity of anemia is shown in Fig. 2.

Nutritional status of study participants was also assessed where, $75 \%$ of them were found to be undernourished and only $3.6 \%$ were overweight/obese (Table 1). As far as gender-wise distribution of malnutrition among study participants was concerned, a significantly higher proportion of females $(80 \%)$ were undernourished in comparison to males (71\%). The odds of suffering from malnutrition (under nutrition and over nutrition combined) were 1.7 times higher among females in comparison to males $(\mathrm{OR}=1.7 ; 95 \% \mathrm{CI}=1.2-2.6)$.

Further while assessing morbidity among study participants it was found that 221 (36\%) of adolescents suffered from any infectious disease in the past 3 months. Among them majority, i.e., 57\% suffered from PUO followed by respiratory tract infections which were seen in $56 \%$ of study participants. Distribution of various diseases from which the study participants suffered from in the past 3 months is shown in Table 2.

Univariate analysis was done to determine the various factors associated with under-nutrition among adolescents (Table 3) where it was observed that going to school (OR=1.6; 95\% $\mathrm{CI}=1-2.3)$ and not being involved in any kind of job/occupation (OR=2.0; 95\% CI=1.2-3.2) were found to be associated with under nutrition. Further, odds of being underweight were 1.5 times $(\mathrm{OR}=1.5 ; 95 \% \mathrm{CI}=1-2.3)$ and 1.8 times $(\mathrm{OR}=1.8 ; 95 \% \mathrm{CI}=1.2-2.8)$ higher among those who suffered from disease in the past 3 months and were female by sex, respectively.

Among those doing any job $(n=103)$, mean age of starting a job was found to be $10.9 \pm 1.6$ years. Going to school (OR=9.1; $95 \% \mathrm{CI}=4.1-20$ ) and being involved in any job/occupation (OR=8.9; $95 \% \mathrm{CI}=4.8-16.3)$ were found to be strongly associated with addiction among the study participants (Table 4).

\section{DISCUSSION}

The present study was conducted among adolescents aged between 10 and 16 years residing in urban slums of Amritsar district where

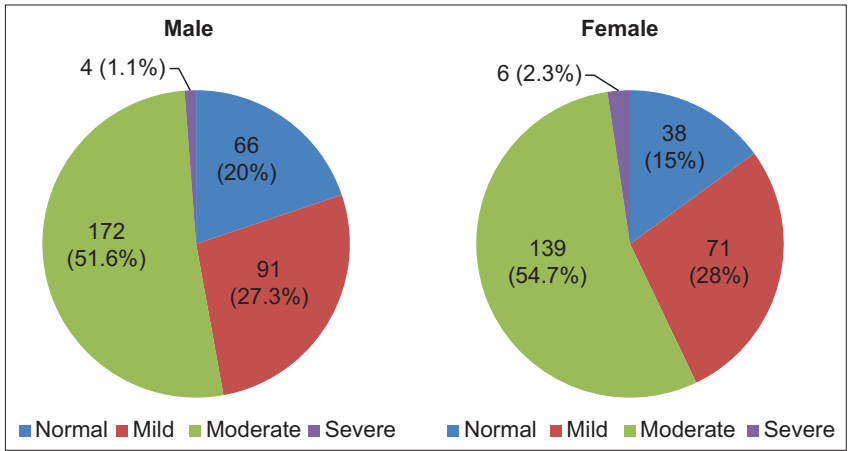

Fig. 2: Gender wise distribution of anaemia according to severity among study participants (aged 10-16 years) 
Table 1: Gender wise distribution of study participants (10-16 years) according to nutritional status based on BMI $(n=603)$

\begin{tabular}{llll}
\hline Nutrition & $\begin{array}{l}\text { Male } \\
(\mathbf{n = 3 3 9 )}\end{array}$ & $\begin{array}{l}\text { Female } \\
(\mathbf{n = 2 6 4 )}\end{array}$ & $\begin{array}{l}\text { Total } \\
(\mathbf{n = 6 0 3 )}\end{array}$ \\
\hline Normal & $86(25)$ & $43(16)$ & $129(21)$ \\
Undernourished & $241(71)$ & $211(80)$ & $452(75)$ \\
Overweight/Obese & $12(3.5)$ & $10(4)$ & $22(4)$ \\
\hline
\end{tabular}

*Figures in parenthesis are percentages; $p=0.006$, Chi-square $=7.278$. BMI: Body mass index

Table 2: Distribution of adolescents according to the type of disease suffered in the last 3 months

\begin{tabular}{lll}
\hline Suffered from disease & Frequency & Percent \\
\hline PUO & 125 & 57 \\
Respiratory tract infection & 123 & 56 \\
Dental caries & 41 & 19 \\
Scabies and other skin infections & 37 & 17 \\
Diarrhoea & 20 & 9 \\
Ear infections & 18 & 8 \\
Tuberculosis & 11 & 5 \\
Others & 31 & 14 \\
\hline
\end{tabular}

$\mathrm{n}=221, *$ Multiple responses

Table 3: Univariate analysis of various socio-demographic and epidemiological factors associated with underweight among study participants (10-16 years)

\begin{tabular}{|c|c|c|c|c|}
\hline Variable & $\begin{array}{l}\text { Underweight } \\
n=452\end{array}$ & $\begin{array}{l}\text { Normal } \\
n=129\end{array}$ & $\begin{array}{l}\text { cOR } \\
(95 \% \mathrm{CI})\end{array}$ & p-value \\
\hline \multicolumn{5}{|c|}{ Goes to School } \\
\hline Yes & $264(81 \%)$ & $60(19 \%)$ & \multirow{2}{*}{$\begin{array}{l}1.6 \\
(1-2.3)\end{array}$} & \multirow{2}{*}{0.016} \\
\hline No & $188(73 \%)$ & $69(27 \%)$ & & \\
\hline \multicolumn{5}{|c|}{ Occupation } \\
\hline No & $386(80 \%)$ & $96(20 \%)$ & \multirow{2}{*}{$\begin{array}{l}2 \\
(1.2-3.2)\end{array}$} & \multirow[t]{2}{*}{0.0039} \\
\hline Yes & $66(67 \%)$ & $33(33 \%)$ & & \\
\hline \multicolumn{5}{|l|}{ Addiction } \\
\hline Present & $35(71 \%)$ & $14(29 \%)$ & \multirow{2}{*}{$\begin{array}{l}0.68 \\
(0.3-1.3)\end{array}$} & \multirow[t]{2}{*}{0.2} \\
\hline Absent & $417(78 \%)$ & $115(22 \%)$ & & \\
\hline \multicolumn{5}{|l|}{ Anemia } \\
\hline Present & $362(78 \%)$ & $105(22 \%)$ & \multirow{2}{*}{$\begin{array}{l}0.99 \\
(0.5-1.6)\end{array}$} & \multirow[t]{2}{*}{0.9} \\
\hline Absent & $76(78 \%)$ & $22(22 \%)$ & & \\
\hline \multicolumn{5}{|c|}{ Disease last $3 \mathrm{~m}$} \\
\hline Yes & $174(82 \%)$ & $37(18 \%)$ & \multirow{2}{*}{$\begin{array}{l}1.5 \\
(1-2.3)\end{array}$} & \multirow[t]{2}{*}{0.04} \\
\hline No & $278(75 \%)$ & $92(25 \%)$ & & \\
\hline \multicolumn{5}{|l|}{ Sex } \\
\hline Female & $211(84 \%)$ & $41(16 \%)$ & \multirow{2}{*}{$\begin{array}{l}1.8 \\
(1.2-2.8)\end{array}$} & \multirow[t]{2}{*}{0.002} \\
\hline Male & $241(73 \%)$ & $88(27 \%)$ & & \\
\hline
\end{tabular}

*(Overweight and obese not included, 8 children). ${ }^{*} \mathrm{p}<0.05$ was considered to be significant. CI: Confidence interval

Table 4: Social factors associated with addiction among adolescents of age 10-16 years residing in urban slums

\begin{tabular}{lllll}
\hline $\begin{array}{l}\text { Social } \\
\text { Factors }\end{array}$ & $\begin{array}{l}\text { Addiction } \\
\text { present } \\
(\mathbf{n = 5 2 )}\end{array}$ & $\begin{array}{l}\text { Addiction } \\
\text { absent (n=551) }\end{array}$ & $\begin{array}{l}\text { c0R } \\
(\mathbf{9 5 \%} \text { CI) }\end{array}$ & p-value \\
\hline $\begin{array}{l}\text { Schooling } \\
\quad \text { No }\end{array}$ & $45(16 \%)$ & $228(84 \%)$ & 9.1 & 0.00001 \\
$\quad \begin{array}{l}\text { Yes } \\
\text { Occupation }\end{array}$ & $7(2 \%)$ & $323(98 \%)$ & $(4.1-20)$ & \\
$\quad$ Yes & $30(29 \%)$ & $73(71 \%)$ & 8.9 & 0.0001 \\
No & $22(4 \%)$ & $478(96 \%)$ & $(4.8-16.3)$ & \\
\hline
\end{tabular}

${ }^{*} \mathrm{p}<0.05$ was considered to be significant. CI: Confidence interval

most of them (80\%) had migrated from other states and belonged to upper lower socio-economic status (94.4\%).
Overall prevalence of anaemia was found to be $82.3 \%$ and it was slightly higher among females (85\%) in comparison to males $(80 \%)$ but the difference was not statistically significant. This is almost double than what has been reported by UNICEF, where $40 \%$ of girls and $18 \%$ of boys were anaemic [7]. This huge variation can be attributed to the difference in the population included in our study. Those residing in urban slums are exposed to poor environment and sanitary conditions as well as belong to poor socio-economic status because of which they fail to fulfill their nutritional requirements pushing them more towards iron deficiency anaemia.

National nutritional monitoring bureau (NNMB) reported a relatively higher prevalence of anaemia among girls aged $12-14$ years $(69 \%)$ as well as those aged 15-17 years (71\%) which was somewhat similar to our study [12].

As far as severity of anaemia was concerned majority in our study suffered from moderate anaemia (53\%), which was higher than studies conducted in other parts of country $[13,14]$.

Proportion of those suffering from severe anaemia (1.7\%) in our study was similar to those reported by NNMB (1-2\%) as severe anaemia is usually seen among those who suffer from chronic ailments like kidney disorders whose prevalence is not affected much by living conditions and socio-economic status.

Almost three fourth of study participants (75\%) were found to be undernourished and it was significantly higher among females (80\%) in comparison to males. Overweight and obesity was observed in only $3.6 \%$ of study participants.

These results were in concordance with the report of UNICEF on malnutrition which reported that $80 \%$ adolescents of India suffer from hidden hunger [7] (one or more nutritional deficiency) and 50\% of those aged 10-19 years are malnourished. As present study was conducted in urban slum settlements, these residing more vulnerable to infectious disease, poor environmental conditions and food insecurity, which contribute greatly towards under-nutrition.

According to our study, those who were going to school, not involved in any occupation/job, female by sex and those who suffered from any infectious disease in last 3 months were at a greater risk of being underweight. Similar findings have been highlighted in studies conducted in Ethopia and Assam $[15,16]$. Proportion of underweight was lesser among those who were involved in any occupation/job were (67\%) in comparison to those not working as doing a job helps them to earn and gives them a freehand to use money earned where it can be utilized to buy food which decreases the risk of being underweight. No study has explored this perspective.

On the other they could also use this money to buy drugs, as in our study adolescents doing job were at 8.9 times higher risk of having addiction to any substance in comparison to those not earning or doing any job. Peer pressure, working conditions, family environment etc. are additional factors which may also contribute for addiction.

As far as substance abuse is concerned, only males (15.2\%) were doing so in our study, which was quite less than that reported by study conducted among adolescents in New Delhi where prevalence of substance use was reported to be $55.4 \%$ of the study population but similar proportions were reported as far as profile of substance use was concerned. Majority used tobacco (77\%) and alcohol (12\%) [17]. Higher proportion of substance use can be due to easily availability and easily accessibility of substance in metropolitan cities like Delhi. Similar results were reported by a study conducted in West Bengal where substance use was observed in $12.5 \%$ of students [18].

As adolescents are in transition phase, their decisive behavior makes them susceptible to substance use. Not going to school and being involved in any work were found to be strongly associated with 
substance use, which is similar to that reported by studies from different parts of country $[17,19]$

About $57 \%$ of children suffer from one or more infectious disease in last 3 months, where fever (57\%), respiratory tract infection (56\%) and skin infections $(17 \%)$ were most common. Similar finding were seen in various studies conducted in various parts of country $[15,16]$ except respiratory tract infection (56\%) which is much higher in our study. It could be due to overcrowding as generations are forced to live in same room due to poor socio-economic condition and living standards of those residing in urban slums. Further under-nutrition contributes to low immunity and as high as $75 \%$ of study participants in our study were under nutrition. High prevalence of under-nutrition (75\%) and anaemia $(82.3 \%)$, Child labor(17\%), early initiation of substance abuse $(9 \%)$, school dropouts (45\%), morbidity related to communicable diseases (36\%) among adolescents (10-16 years of age) found in our study reflects inequitable distribution of resources and poor environmental conditions in urban slums. As under-nutrition is one of indicator of inequality/faulty distribution of wealth in society, as in India top $1 \%$ of the population now holds $73 \%$ of the wealth. In such circumstances most humane suggestions, measures and ideas, wishes can't change the real things until this profit-centered socio-economic system is not replaced with a human-centered system.

\section{CONCLUSION}

High prevalence of under-nutrition and anemia in our study reflects inequitable distribution of resources, low purchasing capacity of foods, and unequal food sharing patterns in families making them socially and biologically Working toward more equitable socio-economic system is ultimate solution of problem.

\section{AUTHORS' CONTRIBUTIONS}

Jasmeet Singh: He was involved in the planning of the study, and writing, reviewing, and editing of the manuscript. Sanjeev Mahajan: He was involved in writing, reviewing and collection of data. S. S. Deepti: She was involved in collecting and analyzing the data. Tejbir Singh: He was involved in writing, reviewing and collection of data. Ruchika: She was involved in writing, reviewing and collection of data. Preeti Padda: She was involved in writing, collecting, analyzing the data and correspondence with journal as corresponding author.

\section{CONFLICTS OF INTEREST}

The authors affirm no conflicts of interest, finance, or otherwise.

\section{AUTHORS' FUNDING}

No external funds were received for this research.

\section{REFERENCES}

1. Chandramouli C. Population Enumeration Data (Final Population) India. New Delhi: Registrar General and Census Commissioner of India; 2011. Available from: https://www.un.org/en/development/ desa/population/events/pdf/expert/23/Presentations/EGM-S2Chandramouli\%20presentation.pdf. [Last accessed on 2021 May 02].
2. Cities Will Account for Over $70 \%$ of India's GDP by 2030 . India Infoline News Service; 2011. Available from: http://www.indiainfoline. $\mathrm{com} / \mathrm{markets} /$ news/cities-will-account-for-over-70-percent-of-indiasgdp-by-2030/5252593577. [Last accessed on 2021 May 07].

3. Primary Census Abstract for Slum. New Delhi: Registrar General and Census Commissioner of India; 2011. p. 40. Available from: https:// www.censusindia.gov.in/2011-Documents/Slum-26-09-13.pdf. [Last accessed on 2021 May 07]

4. Global Hunger Index by Severity; 2020. Available from https://www. globalhungerindex.org/ranking.html. [Last accessed on 2021 May 04].

5. National Family Health Survey (NFHS-3). Mumbai: International Institute for Population Sciences; 2007. P. 588. Available from: http:// www.rchiips.org/nfhs/nfhs3.shtml. [Last accessed on 2021 May 04].

6. Adolescents in India a Desk Review of Existing Evidence and Behaviours, Programmes and Policies. New Delhi: Population Council and UNICEF; 2013. p. 100. Available from: https://www.in.one.un.org/ wp-content/uploads/2016/09/Adolescents in India.pdf. [Last accessed on 2021 May 04].

7. UNICEF. Almost All Adolescents in India are Malnourished: UNICEF; 2019. Available from: https://www.livemint.com/news/india/almostall-adolescents-in-india-are-malnourished-unicef-11572524523471. html. [Last accessed on 2021 May 04].

8. Kessler RC, Angermeyer M, Anthony JC. Lifetime prevalence and age-of-onset distributions of mental disorders in the World Health Organization's world mental health survey initiative. World Psychiatry 2007;6:168-76.

9. Juyal R, Bansal R, Kishore S, Negi KS, Chandra R, Semwal J. Substance use among intercollege students in district Dehradun.J Community Med 2006;31:251-4.

10. The Asia Pacific Perspective Redefining Obesity and its treatment. Geneva: World Health Organization; 2000. Available from: https:// www.apps.who.int/iris/handle/10665/206936. [ Last accessed on 2021 May 08].

11. Ghai OP. Haematological disorders. In: Essential Paedriatics. $6^{\text {th }}$ ed., Ch. 12. Dr. New Delhi: Ghai Delhi Publication; 2009. p. 298.

12. Diet and Nutritional Status of Rural Population and Prevalence of Hypertension among adults in Rural Areas. Hyderabad: NNMB; 2006. Report No.: 24. Available from: https://www.nin.res.in/downloads/ NNMBReport06Nov20.pdf. [Last accessed on 2021 May 08].

13. Siva PM, Sobha A, Manjula VD. Prevalence of anaemia and its associated risk factors among adolescent girls of Central Kerala.J Clin Diag Res 2016;10:LC19-23.

14. Asher T, Shobana M, Abarna A, Aamina A, Bharathi, Chandy P. The Prevalence of Anemia among the Adolescent Girls in a Selected College in Kanchipuram. Med Legal Update 2020;20:28-32.

15. Barman P, Mahanta TG, Barua A. Social health problem of adolescent girls aged 15-19 years living in slums of Dibrugarh town, Assam. Clin Epidemiol Glob Health 2015;3:49-53.

16. Assefa $H$, Belachew $T$, Negash L. Socioeconomic factors associated with underweight and stunting among adolescents of Jimma Zone, South West Ethiopia:A cross-sectional study. Int Schl Res Notices 2013;2013:238546.

17. Daniel LT, Krishnan G, Gupta S.A study to assess the prevalence and pattern of substance use among male adolescents in sub urban area of Delhi. Indian J Soc Psychiatry 2017;33:208-12.

18. Tsering D, Pal R, Dasgupta A. Substance use among adolescent high school students in India:A survey of knowledge, attitude, and opinion.J Pharm Bioallied Sci 2010;2:137-40.

19. Dhawan A, Pattanayak RD, Chopra A, Tikoo VK, Kumar R. Pattern and profile of children using substances in India: Insights and recommendations. Natl Med J India 2017;30:224-9. 